\title{
Evaluation of Matrix Effects of Polycarboxylic Acid Introduction in Inductively Coupled Plasma Atomic Emission Spectrometry (ICP-AES)
}

\author{
Sanda Rončević* and Lovorka Pitarević Svedružić
}

\author{
Laboratory of Analytical Chemistry, Department of Chemistry, Faculty of Science, University of Zagreb, Croatia
}

RECEIVED FEBRUARY 29, 2012; REVISED AUGUST 21, 2012; ACCEPTED SEPTEMBER 16, 2012

\begin{abstract}
In order to establish prerequisite conditions for hyphenation of inductively coupled plasmaatomic emission spectrometry with liquid chromatography, the effects on plasma signal by loading of low concentrated solutions of tartaric, citric and dipicolinic acid were studied. The intensities of $\mathrm{Mn}, \mathrm{Li}, \mathrm{Mg}$, $\mathrm{Cd}$ and $\mathrm{Cu}$ lines were observed in axial and radial signal collection mode. Influences of different ligand concentrations on excitation conditions compared to water were evaluated on the basis of signal-tobackground ratio (SBR) and limits of detection (LOD). Lower LOD values were established in the solutions of tartaric and citric acid than in water solution. Higher values were observed in solutions of dipicolinic acid. The Mg II / Mg I line intensity ratio was calculated in order to compare the changes in excitation conditions. Polycarboxylic acid matrices showed slightly departures from equilibrium conditions $(\approx 3 \%)$ in radial observation mode. The effects of polycarboxylic acids monitored on ionic and atomic lines of $\mathrm{Cd}$ and $\mathrm{Cu}$ were of more complex nature which regards to the type of compound and concentration of the acid solution.(doi: 10.5562/cca2066)
\end{abstract}

Keywords: ICP-AES, matrix effects, citric acid, tartaric acid, dipicolinic acid

\section{INTRODUCTION}

Inductively coupled plasma spectrometry either with optical (ICP-AES) or mass detection (ICP-MS) when hyphenate with high-performance liquid chromatography (HPLC) allows on-line preconcentration, separation and detection of trace metals in complex samples. The excellent ability of method in separation of metals at low concentration level is approved in environmental assessment and moreover in analytical speciation. Due to their strong complexing ability, polycarboxylic acids are the most common organic ligands used in metal separation purposes. Tartaric, citric and dipicolinic acid dissolved in water usually served as mobile phases in ion-chromatography. There are number of publications which describe their use in metal separation by ionchromatography, but much less when hyphenated technique is applied. ${ }^{1-5}$ Major interest in this area is still oriented towards improvement in the separation step. The influence of rising concentration of tartaric acid was studied in the determination of hydride forming elements like germanium and tin. ${ }^{6,7}$ It was also found that separations of divalent cations are significantly improved with rising concentrations of tartaric acid. ${ }^{8}$ Considerable attention is paid to metal complexes with citric acid, because they play a significant role in plant growth ${ }^{9}$ and environmental systems. ${ }^{10}$ Dipicolinic acid, as terdentate ligand, forms anionic complexes with a number of transition metals and rare-earth elements in mobile phase solution or in chelating surface of impregnated resins, either. ${ }^{1,2}$ However, the lack of detection sensitivity in hyphenated HPIC-ICP systems which is often connected with dilution effects, arise also from poor plasma tolerance on organic matter introduction. The studies of effects of acetic acid and organic amines introduction into plasma are frequently presented. ${ }^{11-13}$ Despite their importance in speciation purposes, ${ }^{14,15}$ there is a lack of data denotes to polycarboxylic acid effects in plasma spectrometry.

Organic solvent introduction into plasma is challenging analytical problem in plasma spectrometry. Matrix interferences of such solvents have not yet been fully explained beside the fact that comprehensive studies with different approaches have been performed. Basic considerations within this field of interest deal with influences of physical properties of solution on aerosol formation. ${ }^{16-18}$ Changes of surface tension, relative volatility and viscosity of organic solutions compared to water, affect the droplet distribution in sample introduction system and consequently, the amount of analyte that reaches the plasma. However, this is the only one side of the organic matter introduc-

\footnotetext{
* Author to whom correspondence should be addressed. (E-mail: roncevic@chem.pmf.hr)
} 
tion effects in ICP. The complexity of organic matter impact is also accomplished by entering of solutions into plasma when changes in the temperature and the electronic density of plasma take place. Generally, the organic solvents affect the elements emission signal which results with enhancement or suppression of intensity. This mostly depends on the type of solvent, on type of dissolved organic compound ${ }^{19-23}$ and on instrument conditions. ${ }^{11,24} \mathrm{By}$ introducing the concept of robust plasma conditions when matrix composition changes do not significantly deteriorate analytical signal, a relatively simple experiment of measuring the $\mathrm{Mg}$ II / Mg I line intensity ratio as an indicator for robustness was proposed. ${ }^{25}$ Some investigations of matrix effects involving $\mathrm{Mg}$ ratio measurements mainly describe the effects of easily ionized elements (EIE) on signal behaviour, ${ }^{26,27}$ as well as the effects of inorganic acids as the most common matrices in plasma spectrometry analyses. ${ }^{12-14,28,29}$ Also, the studies of axially and radially viewed plasma comprise examinations of analyte detection limit, as another figure of merit. ${ }^{30-32}$ Generally, it is recommendable to use axially viewed configuration for applications requiring better sensitivity, but without a complex matrix. For samples with complex matrices, the best option is use of radially viewed configuration. However, the robust plasma conditions ( $\mathrm{Mg}$ II / Mg I > 8) need to be preserved in both viewing modes. ${ }^{13}$ Recent reviews on applications of robustness concept in hyphenated techniques show that there is no single way to eliminate the complexity of organic matrix effects in plasma. ${ }^{33,34}$ The procedures can be devised to identify matrix effects and either eliminate or compensate them.

In this work, the effects of low concentrated solutions of tartaric, citric and dipicolinic acid, which are common ligands in separation of transition metals by ion chromatography, were studied after introduction into ICP-AES instrument. Assuming possible changes in plasma excitation conditions after aspiration of solutions of selected acids, signal intensities on several emission lines were measured in water and polycarboxylic acid solutions. The prominent $\mathrm{Mn}$ and $\mathrm{Li}$ lines were chosen as representative "hard" and "soft" lines, ${ }^{35}$ ionic and atomic $\mathrm{Mg}$ lines as diagnostic lines; ionic and atomic $\mathrm{Cd}$ lines as representative of lines with greater sum of $E_{\text {exc }}$ and $E_{\text {ion }}$; and $\mathrm{Cu}$ lines as representative of elements with significantly different $E_{\text {exc }}$ of ionic and atomic lines. The experiment involved measurements in both plasma viewing modes, i.e. axial and radial. Influences of organic acids concentrations on excitation conditions compared to water were evaluated on the basis of signal-to-background ratio (SBR) and limits of detection (LOD). Therefore, the estimated magnitude of the observed effects could serve for the selection of optimal conditions when low concentration polycarboxylic acid solution in aqueous media are intoduced into plasma.

\section{EXPERIMENTAL}

A Teledyne Leeman Labs. (Hudson, NH, USA) Prodigy High Dispersion ICP system was used for this study. The system is equipped with $40 \mathrm{MHZ}$ "free-running" radiofrequency generator and echelle grating based spectrometer with a large-format programmable array detector (L-PAD). Nebulization was performed with a glass concentric nebulizer and a glass cylonic spray chamber. The dual-view torch for observing both axial and radial position was used. The solution uptake rate was adjusted on $1 \mathrm{~mL} \min ^{-1}$. In all experiments the r.f. power of $1.2 \mathrm{~kW}$, and flow rates of argon (coolant $18 \mathrm{~L}$ $\mathrm{min}^{-1}$, auxiliary $0.8 \mathrm{~L} \mathrm{~min}^{-1}$ ) were held constant. The integration time was adjusted to $10 \mathrm{~s}$ for all lines in dual-view mode. Signal acquisition was repeated three times throughout the measurements. The precision of intensity measurements on chosen analytical lines in aqueous solution comprises $0.1-0.5 \%$ RSD. Ionic and atomic lines of different excitation and ionization potential were choosen for the monitoring of intensity behaviour. The images of selected lines on the L-PAD detector showed no spectral interferences. The selected lines along with transition data are listed in Table 1.

High purity deionised water (Milli-Q Element system, Millipore, USA) was used. Nitric acid (Suprapure, Merck, Germany) diluted to $2 \% v / v$ was used for aqueous solutions preparation. Analytical grade compounds of tartaric (Merck, Germany), citric (Merck, Germany) and dipicolinic acid (Fluka, Switzerland) were used. Solutions of polycarboxylic acids were prepared by dissolution of proper weight of analytical grade compounds into water. The final concentrations were 0.5 and $1.0 \% \mathrm{w} / \mathrm{v}$ for tartaric and citric acid solutions; and 0.05 and $0.1 \% \mathrm{w} / v$ for dipicolinic acid solutions. Single element standard solutions of $\mathrm{Mg}, \mathrm{Mn}$, $\mathrm{Li}, \mathrm{Cu}$, and Cd (Plasma Pure, Leeman Labs, USA) were used for the control of plasma positioning and preparation of model solutions. Test solutions for the examination of acid effects were prepared from stock solutions $\left(1 \mathrm{~g} \mathrm{~L}^{-1}\right)$ by appropriate dilution and contained $0.1 \mathrm{mg} \mathrm{L}^{-1}, 1.0 \mathrm{mg} \mathrm{L}^{-1}, 2.5 \mathrm{mg} \mathrm{L}^{-1}, 8.0 \mathrm{mg} \mathrm{L}^{-1}$ and 10 $\mathrm{mg} \mathrm{L}^{-1}$ of selected metals in each aqueous acid solution. The multielement solution in water was prepared from single element stock solutions in same manner.

Measurements were performed in series starting from lower concentrations of analyte and of lower content of organic matrix and by aspirating the solutions through peristaltic pump at fixed flow of $1 \mathrm{~mL} \mathrm{~min}$. Radiofrequency power was optimized by measuring the manganese intensity in the range of $0.7-1.5 \mathrm{~kW}$. The rinsing of sample introduction system by $5 \% v / v$ nitric 
Table 1. Elements and lines selected for organic acids effects study

\begin{tabular}{cccc}
\hline Element line & $\begin{array}{c}\text { Wavelength } \\
\lambda / \mathrm{nm}\end{array}$ & $\begin{array}{c}\text { Excitation energy } \\
E_{\text {exc }} / \mathrm{eV}\end{array}$ & $\begin{array}{c}\text { Ionization energy } \\
E_{\text {ion }} / \mathrm{eV}\end{array}$ \\
\hline Mn II & 257.610 & 4.81 & 7.44 \\
Li I & 670.784 & 1.90 & 5.39 \\
Cu I & 324.754 & 3.82 & 7.72 \\
Cu II & 224.700 & 5.51 & - \\
Cd I & 214.441 & 5.41 & 8.99 \\
Cd II & 228.802 & 5.78 & - \\
Mg I & 285.213 & 4.43 & 7.65 \\
Mg II & 280.270 & 4.42 & - \\
\hline
\end{tabular}

acid was performed through $5 \mathrm{~min}$ after each change of polycarboxylic acid matrix. There were no visible carbon deposition on plasma torch during all performed measurements.

\section{RESULTS AND DISCUSSION}

\section{Testing of Plasma Tolerance}

Several preliminary investigation steps were performed to define suitable operation of ICP-AES instrument when introducing solutions of different concentrations of polycarboxylic acids. The signal of manganese, which is used for plasma spectrometer positioning, was scanned in the range of $0.7-1.5 \mathrm{~kW}$ of applied radiofrequency power. By comparison of scanned manganese intensity in water and polycarboxylic acids solutions, the minimal changes in intensity magnitude were established in the range of 1.1 to $1.3 \mathrm{~kW}$ of r.f. power. Flow rate of solution aspiration into plasma was adjusted at 1

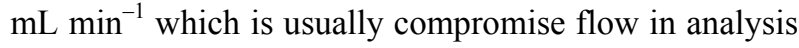
of aqueous solution, and is also the most common flow rate of ion-chromatography effluents. For this reason, solutions of different concentrations of tartaric, citric and dipicolinic acids were aspirated into plasma at fixed flow rate and at fixed r.f. power of $1.2 \mathrm{~kW}$ and changes in reflected power of generator were monitoring. It was found that higher concentrations of tartaric and citric acid do not affect the impendance in electric circuit. Their aspiration through nebulizing system, which is usually applied for the water solution, caused clogging of nebulizer after 2 hours of aspiration with concentrations of dissolved acids higher than $2 \% w / v$. Dipicolinic acid concentrations higher than $0.5 \% \mathrm{w} / v$ caused significant disturbance of reflected power and quenching effects in plasma. For the further more detailed studies low concentrations of acids were chosen. Usually, concentration of $15 \mathrm{mmol} \mathrm{L}^{-1}$ of tartaric and citric acid, and $6 \mathrm{mmol} \mathrm{\textrm {L } ^ { - 1 }}$ of dipicolinic acid in chromatographic separation of metals are enough to obtain adequate resolu- tion. ${ }^{3,4}$ Therefore, the concentrations of polycarboxylic acids in study of the possible effects in plasma were set in the range which covered the most of the separation purposes.

\section{Evaluation of Signal-to-background Ratio and Lim-} its of Detection

Representative "hard" (Mn II 257.610) and "soft" lines (Li I 670.784) were chosen to test signal behaviour in water and polycarboxylic acids solutions. The signalto-background ratio (SBR) determinations for the axial and radial viewing mode were performed. The obtained results presented in Figure 1 show the linear rise of SBR values for both lines. The typical behavior of "soft" $\mathrm{Li}$ atomic line in radial mode was noted. Majority of radiation processes occur in the entrance of plasma channel and therefore, much less radiation entered the spectrometer in radial than in axial mode. Calculated slopes of obtained curves denote to approximate value of 5.9 in axial and 0.8 in radial mode. In opposite, the obtained slopes of curves in axial and radial mode showed almost negligible difference for "hard" Mn line. The slope values were 6.8 for axial and 6.7 for radial viewing mode for the set of measured solutions. It is also evident from the Figure 1 that measured signals in axial and radial mode did not show uniform trend due to rise of organic matter content.

To evaluate the magnitude of the effects of organic matter introduction into plasma the limit of detection (LOD) values as another indicator are proposed. ${ }^{33} \mathrm{Lim}-$ its of detection of $\mathrm{Mn}$ and $\mathrm{Li}$ in water and polycarboxylic acid solutions were determined based on $3 \sigma$ calculation. It can be noted from the Table 2 that the LOD values were lower when introducing solutions of tartaric and citric acid compared to water. LOD values became worse in the solution of $0.1 \%$ dipicolinic acid than in water, which was observed in both viewing modes. Results of measurements (Mn and $\mathrm{Li}$ ) in solutions of 0.5 and $1.0 \%$ tartaric and citric acid show low- 

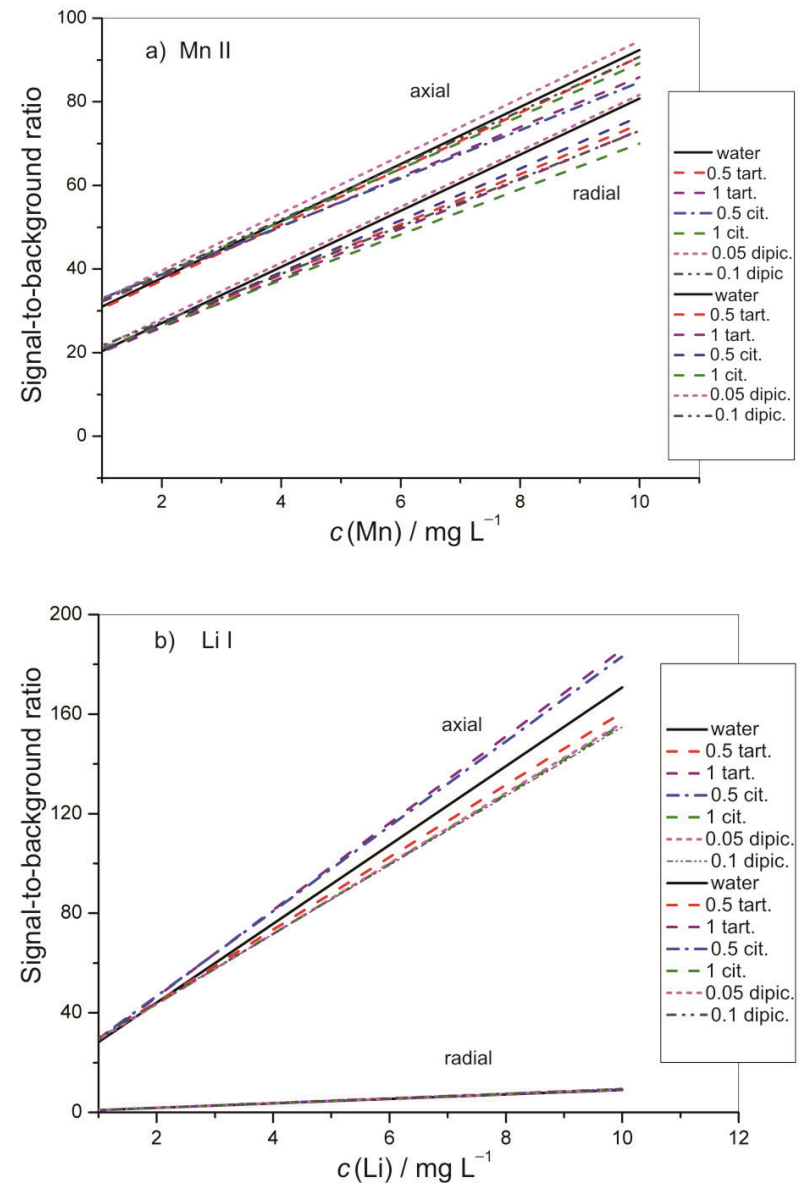

Figure 1. Signal-to-background ratio in polycarboxylic acid solutions

a) $\mathrm{Mn}$ II $257.610 \mathrm{~nm}$

b) Li I $670.784 \mathrm{~nm}$

er LOD values than in water, especially when higher concentrated acid solutions were aspirated. It was assumed that the rise in organic content should degrade detection power, as was in the case of dipicolinic acid. The opposite trends indicate that the analyte concentration and therefore, the net line intensity were positively affected by higher content of tartaric and citric acid. The obtained results suggested possible formation of smaller aerosol particles, and consequently greater amount of analyte in plasma. ${ }^{22}$ However, there were no drastic discrepancies in measured LOD values; they comprised the same order of magnitude and showed that the measuring conditions were slightly different than in water.

\section{Testing the Robustness of Plasma}

Variation in the intensity ratio of selected ionic to atomic line of the same element can be used to define excitation and ionization conditions in plasma. Magnesium lines are the most frequently used for the purpose of explaining local thermodynamic equilibrium conditions (LTE) in plasma. A Mg II / Mg I ratio values above 7-8 indicate existence of LTE conditions, and lower denotes to non-LTE conditions. ${ }^{25}$ A set of instrumental parameters, which can be adjusted to obtain a proper ratio values, define ICP operation in robust mode where minimal deviation regarding different matrix composition occurred.

In this experiment, the fixed operation parameters had included r.f. power of $1.2 \mathrm{~kW}$ and carrier flow rate of $1 \mathrm{~mL} \mathrm{~min}-1$ as the compromise conditions for analysis of aqueous solutions. The solutions of low concentrations of particular polycarboxylic acids which contain $\mathrm{Mg}$ in the range of $1-10 \mathrm{mg} \mathrm{L}^{-1}$ were introduced into plasma. The measured $\mathrm{Mg} \mathrm{II} / \mathrm{Mg}$ I intensity ratio is given in Figure 2. The ratio values obtained for each viewing mode were above threshold indicator for LTE conditions. The higher values $(\approx 11)$ were obtained for the radial viewing mode than for axial $(\approx 8)$. By comparison of the $\mathrm{Mg}$ ratios obtained in polycarboxylic acid solutions with that of water, the variations in the set of organic solutions comprise maximal $3 \%$ of water solution ratio, which indicates slightly disturbance in LTE conditions. Also, the ratio values showed in Figure 2 confirm the fact that radial viewing position is less sensitive to changes in matrix composition than axial. $^{26,31}$

Among the literature data of organic acid matrix effects in plasma, the monocarboxylic acetic acid is the most studied one. Several authors found the higher $\mathrm{Mg}$ ratio for acetic acid solutions. The rise greater than $5 \%$ was found in higher concentrated acid solutions $(>10 \%)$ which was attributed to aerosol formation and transport. ${ }^{11,23,24}$ The production of finer aerosol particles and evaporation processes increase the analyte amount as the concentration of acid rise. The mechanism of transport and aerosol formation is connected closely with physical properties of solutions. In aqueous solu-

Table 2. Limits of detection $\left(\mu \mathrm{g} \mathrm{L}^{-1}\right)$ in water and in dilute polycarboxylic acid solutions

\begin{tabular}{ccccccccc}
\hline & & water & $\begin{array}{c}0.5 \% \\
\text { tartaric }\end{array}$ & $\begin{array}{c}1.0 \% \\
\text { tartaric }\end{array}$ & $\begin{array}{c}0.5 \% \\
\text { citric }\end{array}$ & $\begin{array}{c}1.0 \% \\
\text { citric }\end{array}$ & $\begin{array}{c}0.05 \% \\
\text { dipicolinic }\end{array}$ \\
\hline \multirow{2}{*}{ Mn II } & Axial & 1.04 & 0.78 & 0.68 & 0.55 & 0.71 & 0.91 \\
& Radial & 0.77 & 0.76 & 0.57 & 0.72 & 0.55 & 0.68 \\
Li I & Axial & 1.05 & 0.37 & 0.27 & 0.21 & 0.13 & 1.14 \\
& Radial & 2.14 & 2.08 & 1.65 & 1.89 & 1.29 & 1.19 \\
\hline
\end{tabular}




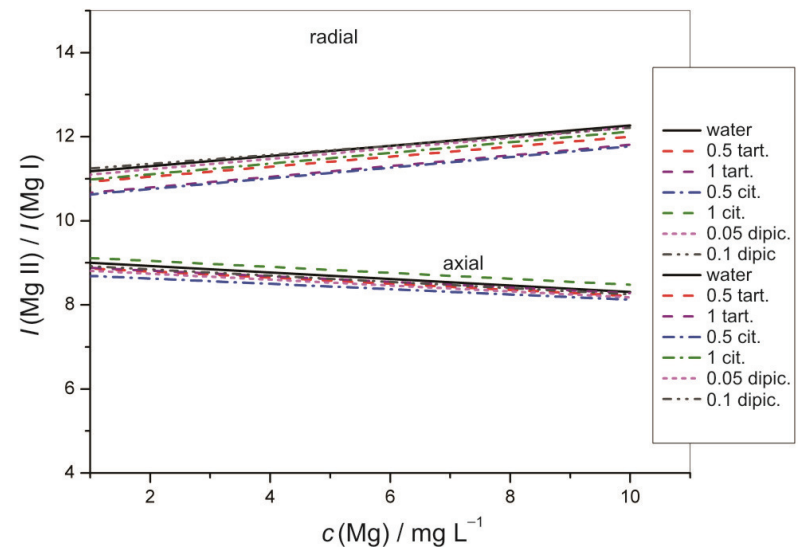

Figure 2. Mg II / Mg I line intensity ratio in polycarboxylic acid solutions for axial and radial mode of signal observation.

tions of low concentration of organic acid, the changes in physical parameters should not be considered as the most crucial, because their values are close to that of water. The recent data in acetic acid effect studies show that concentrations lower than $0.7 \% \mathrm{w} / v$ did not significantly affect the $\mathrm{Mg}$ ratio. ${ }^{14}$

Solutions of polycarboxylic acids studied in this work were of lower concentration than those of acetic acid reported in literature, though the same explanation could partially be accepted. Slight rise in $\mathrm{Mg}$ ionic/atomic line ratio is measured only in $1 \%$ citric and $0.1 \%$ dipicolinic acid solutions. The lower ratio values in the rest of measured solutions show the different kind of effects compared to acetic acid. This might be attributed to the nature of polycarboxylic compounds which cause different carbon load. Also, a higher abundance of hydroxyl groups might impact the excitation and also the ionization processes in plasma in the greater extent.

\section{Matrix effects on $\mathrm{Cu}$ and $\mathrm{Cd}$ Emission Lines}

In order to test plasma performances for the possible hyphenation purposes, the polycarboxylic acids effects were also monitored on ionic and atomic lines of $\mathrm{Cd}$ and $\mathrm{Cu}$. As was already stated by Nesterenko et al., there were only few reports of polycarboxylic acid use in ion chromatography separation of metals as negatively charged complexes. ${ }^{36}$ They evaluate separation of negatively charged citrate complexes in ion chromatography. The use of several polycarboxylic acids in $\mathrm{Cd}$ speciation by hyphenated HPLC and ICP-MS shows great potential in the determination of species bioavailability, despite neglecting of organic matrix load into plasma. ${ }^{37}$ To evaluate the effects of organic matrix load into plasma we have measured SBR values for solutions containing $10 \mathrm{mg} \mathrm{L}^{-1}$ of each element in tartaric, citric and dipicolinic acid and made comparison to SBR in aqueous solution. The results given in Table 3 show SBR values normalized to water values. If particular acid is taken in consideration, some interesting observations could be drawn from the obtained results. In tartaric acid solutions, the greater discrepancies from water values were found for $\mathrm{Cd}$ lines in axial and radial mode. The higher concentration of tartaric acid caused more pronounced effect of rising value on $\mathrm{Cd}$ atomic line in axial mode. It also seems that $\mathrm{Cu}$ lines were less affected in radial than axial mode, because the SBR values did not show such variations as those of $\mathrm{Cd}$ lines.

Rising concentration of citric acid caused decrease in SBR values on atomic lines of $\mathrm{Cd}$ and $\mathrm{Cu}$ in both viewing modes; their values, except the $\mathrm{Cu}$ I line in

Table 3. Signal-to-background ratio for tested solutions normalized to water

\begin{tabular}{|c|c|c|c|c|c|c|c|}
\hline & water & $\begin{array}{c}0.5 \% \\
\text { tartaric }\end{array}$ & $\begin{array}{l}1.0 \% \\
\text { tartaric }\end{array}$ & $\begin{array}{l}0.5 \% \\
\text { citric }\end{array}$ & $\begin{array}{l}1.0 \% \\
\text { citric } \\
\end{array}$ & $\begin{array}{c}0.05 \% \\
\text { dipicolinic }\end{array}$ & $\begin{array}{c}0.1 \% \\
\text { dipicolinic } \\
\end{array}$ \\
\hline \multicolumn{8}{|l|}{ Axial } \\
\hline $\mathrm{Cu} \mathrm{I}$ & 1 & 1.085 & 1.014 & 1.048 & 0.989 & 1.049 & 1.095 \\
\hline $\mathrm{Cu}$ II & 1 & 1.066 & 1.035 & 1.085 & 1.074 & 1.035 & 0.998 \\
\hline $\mathrm{Cd} \mathrm{I}$ & 1 & 1.092 & 1.483 & 1.084 & 0.835 & 1.057 & 0.847 \\
\hline Cd II & 1 & 1.023 & 1.022 & 1.030 & 1.032 & 1.030 & 1.014 \\
\hline \multicolumn{8}{|c|}{ Radial } \\
\hline $\mathrm{Cu} \mathrm{I}$ & 1 & 1.078 & 1.032 & 1.044 & 1.041 & 1.003 & 1.006 \\
\hline $\mathrm{Cu}$ II & 1 & 1.024 & 1.005 & 1.016 & 1.045 & 1.039 & 1.023 \\
\hline $\mathrm{Cd} \mathrm{I}$ & 1 & 1.066 & 1.110 & 1.041 & 0.840 & 1.055 & 1.031 \\
\hline Cd II & 1 & 1.027 & 1.126 & 1.071 & 1.226 & 1.205 & 1.119 \\
\hline
\end{tabular}


radial mode, were under normalized water value. Ionic line of $\mathrm{Cd}$ measured in radial mode is most affected by introducing $1 \%$ of citric acid solution. Dipicolinic acid, which contains heterocyclic pyridine ring, influenced SBR ratio in different manner. The greater positive rise compared to normalized water values were found in the case of $0.05 \%$ solution for all measured lines. Introduction of $0.1 \%$ dipicolinic acid solution lower the SBR ratio for $\mathrm{Cu} \mathrm{II}$ and $\mathrm{Cd} \mathrm{I}$ lines in axial mode.

Considering relatively close energy of excitation of $\mathrm{Cd}$ lines, and significantly different energy of $\mathrm{Cu}$ lines (Table 1), the greater variations in SBR values were expected for $\mathrm{Cu}$. However, the results were more complex and no simple explanation could be derived from the observing SBR variations. Among the literature data, the investigations of the effects of matrix composition related to plasma excitation mechanisms involve also the properties of optical transition of analytical line. The influences of matrix which contained easily ionizable elements, i.e. alkalis and earth-alkalis elements were often observed. Conclusions on different effects on atomic and ionic lines reveal that ionic lines do not suffer seriously on matrix effects induced by alkali or earth-alkali metals. The properties of lines related to the excitation and the ionization energies and/or charge-transfer processes that occur in plasma were suggested as the source of such behavior. ${ }^{26,27}$ It was already found that the lines having close excitation energy, for example $\mathrm{Cd}$ lines, may exhibit different effects when easily ionized elements are present in plasma. ${ }^{27,38-40}$ In contrast, the copper atomic lines did not show the same sensitivity under similar conditions. ${ }^{38-40}$ In a certain degree, some of the described effects were also noted in present study of polycarboxylic acid matrices. Observation of $\mathrm{Cd}$ and $\mathrm{Cu}$ lines intensity showed the different magnitude of the effects caused by tartaric, citric and dipicolinic acid introduction into plasma. Elimination of matrix influences in practical purposes rely on different approaches like sample pretreatment, alternative introduction system, and various calibration approach as matrix matching and internal standardization. ${ }^{34}$ Therefore, the estimated magnitude of polycarboxylic acid effects in plasma can be very useful in selection of proper analytical strategies for reliable determination of heavy elements in organic matrices.

\section{CONCLUSION}

Low concentrated solutions of polycarboxylic acids, namely tartaric, citric and dipicolinic acid, which are used as the most common mobile phases in chromatographic separation of transition and rare-earth metals, reveal that their introduction into plasma can cause the different effects on emission lines. At the compromise operation parameters adjusted for water solutions, the measured effects are reflected through signal-tobackground values and limits of detection of elements which comprise slightly different values than in water. The changes in Mg II / Mg I ratio when selected acids entered the plasma, implied the disturbance of local thermodynamic equilibrium conditions. Although, the ratio variations compared to water was smalk $\beta \%$ ), the study of $\mathrm{Cd}$ and $\mathrm{Cu}$ ionic and atomic lines behaviour in low concentrated polycarboxylic acid solutions suggest that observed effects are not uniform and mutually comparable. Nevertheless, a number of parameters, i.e. physical and chemical properties of solutions, instrumental conditions, transport mechanisms, and energy related optical transitions need to be included in considerations in order to obtain more reliable conclusions about specific organic acid effects, and finally accurate quantitative determination of selected metal content. This study indicates that the use of polycarboxylic acids in separations and preconcentration of selected metals followed by introduction in ICP needs previous evaluation of magnitude of matrix effects in plasma regarding type of organic compound and its concentration in aqueous solution.

Acknowledgements. The investigation was performed as a part of project 119-1191342-1083 financed by Republic Croatia Ministry of Science, Education and Sport.

\section{REFERENCES}

1. A. I. Elfeterov, S. N. Nosal, P. N. Nestrenko, and O. A. Shpigun, Analyst 119 (1994) 1329-1332.

2. R. M. C. Sutton, S. J. Hill, P. Jones, A. Sanzmendel, and J. I. Garciaalonso, J. Chromatogr. A 816 (1998) 286-291.

3. P. K. Dasgupta, Anal.Chem. 64 (1992) 775A-783A.

4. E. Santoyo, S. Santoyo-Guiterrez, and S. P. Verma, J. Chromatogr. A 884 (2000) 229-241.

5. S. Roncevic and I. Steffan, At. Spectrosc. 25 (2004) 125-132.

6. P. Smichowski and J. Marrero, Anal. Chim. Acta 376 (1998) 283-291.

7. S. Farias, R. E. Rodriguez, A. Ledesma, D. A. Batistoni, and P. Smichowski, Microchem. J. 73 (2002) 79-88.

8. M. Mori, K. Tanaka, M. I. H. Halelah, Q. Xu, M. Ikedo, Y. Ogura, S. Sato, W. Hu, K. Hasebe, and P. R. Haddad, J. Chromatogr. A 997 (2003) 219-224.

9. T. Gasparics, V. G. Mihucz, E. Tatar, and G. Zaray, Microchem. J. 73 (2002) 89-98.

10. O. Happel and A. Seubert, J. Chromatogr. A 1108 (2006) 68-75.

11. J. M. Mermet, J. Anal. At. Spectrom. 13 (1998) 419-422.

12. J. C. J. Silva, N. Baccan, and J. A. Nobrega, J. Braz. Chem. Soc. 14 (2003) 310-315.

13. L. C. Trevizan, E. C. Vieira, A. R. A. Nogueira, and J. A. Nobrega, Spectrochim. Acta B 60 (2005) 575-581.

14. E. Paredes, S. E. Maestre, and J. L. Todoli, Spectrochim. Acta B 61 (2006) 326-339.

15. S. Roncevic and I. Steffan, At. Spectrosc. 23 (2002) 24-31.

16. A. W. Boorn, and R. F. Browner, Anal.Chem. 54 (1982) 1402 1410.

17. M. S. Cresser, and R. F. Browner, Spectrochim. Acta B 35 (1980) 
$73-79$.

18. T. Kumamaru, Y. Okamoto, Y. Yumamoto, F. Nakata, Y. Nitta, and H. Matsuo, Fresenius Z. Anal. Chem. 327 (1987) 777-781.

19. J. A. C. Broekaert, F. Leis, and K. Laqua, Talanta 28 (1981) $745-752$.

20. L. De Galan, Spectrochim. Acta B 39 (1984) 537-550.

21. R. I. Botto, Spectrochim. Acta B 42 (1987) 181-199.

22. T. D. Hettipathirana, A. P. Wade, and M. W. Blades, Spectrochim. Acta B 45 (1990) 271-280.

23. S. Roncevic, and M. Siroki, J. Anal. At. Spectrom. 9 (1994) 99-104.

24. C. Dubuisson, E. Poussel, J. M. Mermet, and J. L. Todoli, J. Anal. At. Spectrom. 13 (1998) 63-67.

25. J. M. Mermet, Anal. Chim. Acta 250 (1991) 85-94.

26. M. Iglesias, T. Vaculovic, J. Studynkova, E. Poussel, and J. M. Mermet, Spectrochim. Acta B 59 (2004) 1841-1850.

27. G. C. Y. Chan and G. M. Hieftje, Spectrochim. Acta B 59 (2004) 163-183.

28. Y. Danzaki and K. Wagatsuma, Anal. Chim. Acta 447 (2001) 171-177.

29. M. Grotti, R. Leardi, and R. Frache, Spectrochim. Acta B 57
(2002) 1915-1924.

30. P. Masson, Spectrochim. Acta B 54 (1999) 603-612.

31. I. B. Brenner and A. T. Zander, Spectrochim. Acta B 55 (2000) 1195-1240.

32. F. V. Silva, L. C. Trevizian, C. S. Silva, A. R. A. Nogueira, and J. A. Nobrega, Spectrochim. Acta B 57 (2002) 1905-1913.

33. M. Popp, S. Hann, and G. Koellensperger, Anal. Chim. Acta 668 (2010) 114-129.

34. C. Agatemor and D. Bauchemin, Anal. Chim. Acta 706 (2011) 66-83.

35. P. W. J. M. Boumans, Inductively Coupled Plasma Emission Spectroscopy, Part I and Part II, Wiley, New York, 1987.

36. E. P. Nesterenko, P. N. Nesterenko, and B. Paull, J. Chromatogr. A 1213 (2008) 62-69.

37. H. Yan, L. Yang, and Q. Wang, Talanta 84 (2011) 287-292.

38. G. C. Y. Chan and G. M. Hieftje, J. Anal. At. Spectrom. 23 (2008) 181-192.

39. G. C. Y. Chan and G. M. Hieftje, J. Anal. At. Spectrom. 23 (2008) 193-204.

40. M. Stepan, P. Musil, E. Poussel, and J. M. Mermet, Spectrochim. Acta B 56 (2001) 443-453. 